\title{
PARAMETRIC STUDY OF AN ACTIVE SOLAR FLAT-PLATE COLLECTOR WATER HEATER
}

\author{
G. A. Duvuna ${ }^{1} *$, Y. I. Tashiwa ${ }^{2}$ and Y. I. Zhigilla ${ }^{3}$

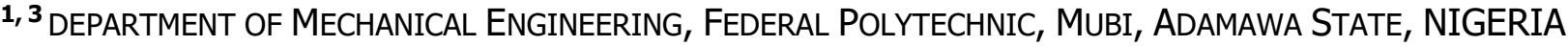

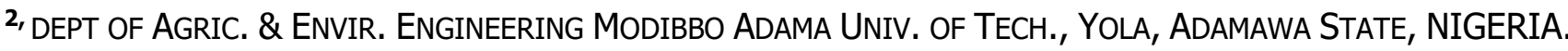 \\ Email addresses: ${ }^{1}$ ayubagideon2@gmail.com, ${ }^{2}$ yaktashiwa@yahoo.com, ${ }^{3}$ yizhigilla@gmail.com
}

\begin{abstract}
Monthly average daily weather data and solar radiations of Bauchi obtained from the weather data processor (Type 109 component) of TRNSYS 16 software were used as the input into the design equations coded using MATLAB programming language to determine the system characteristics and components sizes. Parametric study was carried out to study the effects and sensitivity of varying some design parameters such as collector area and number of glazing, length of collector tube and tube diameter, mass flow rate and volume of the water, air gap spacing between the absorber plate and glazing and the tube spacing and plate thickness on the system solar fraction (f). The results revealed that with collector area of $0.1 \mathrm{~m}^{2}$ to $5 \mathrm{~m}^{2}$ single glazing $82 \%$ solar fraction was achieved and with double glazing, $97 \%$ system solar fraction was achieved. Increasing the length of the tube increases the system solar fraction. This implies that as the number of turns of the flow tube increases the system solar fraction increases but the solar fraction decreases with increase in the diameter of the tank, with tank diameter of $0.1 \mathrm{~m}$ to $0.4 \mathrm{~m}$ an average of $75 \%$ system solar fraction was achieved. As the air gap increases, the top heat loss increases and decreases as the number of glazing increases, an air gap of $0.045 \mathrm{~m}(4.5 \mathrm{~cm})$ to $0.05 \mathrm{~m}(5 \mathrm{~cm})$ was found to be suitable for optimum system performance. Increasing the tube spacing, the system solar fraction decreases but as the plate thickness increases, the system solar fraction increases slightly. This implies that, decreasing the tube spacing leads to increase in system solar fraction. The plate thickness increase is considered very insignificant considering the system cost in relation to system performance.
\end{abstract}

Keywords. Solar fraction, solar radiation, weather data, parametric study, solar collector, MATLAB programming language

\section{INTRODUCTION}

Alternative energy are technical terms to be heard with an over increasing frequency from scientists, engineers, technologies, economics and politicians the world over. One of the major reasons is the scientific findings that, the known stock of traditional source of energy is slowly declining with an ultimate decline of fossil fuels in sight. Yet demand for energy is ever increasing and so it is imperative that, alternative energy sources are found. Indeed it is an established fact that, the level of energy demand of any society is an index of its level of development. Scientists and engineers in many countries are working hard in order to develop new technologies for the economically acceptable utilization of alternative energies. We all have to be realistic and should constantly be aware of the fact that, the gush of oil and gas is limited both in quantity and time. Only the intensive utilization of renewable energy along with energy conservation will enable us to supply enough energy for the demand of the future.

The principles, fundamentals, and operations of solar energy technologies are in two broad categories: namely; solar photovoltaic technologies and solar thermal technology [1]. The former requires the direct application of solar energy to produce heat. Solar photovoltaic (PV) technologies- as in the latter case- is the conversion of solar radiation to electricity for

\footnotetext{
* Corresponding author, tel: +234 - $703-269-2982$
} 
various applications. It is on record that, the Nigeria lying within the tropical belt and close to the equatorial region is endowed with longer hours of sunshine than other nations in the temperate regions [2]. Hence, sun drying of personal effects such as clothing and drying of agricultural commodity among others are common place practices and has promoted leading research endeavours in thermal equipment like cabinet dryer, oven, hatchery, water heaters among others. In Nigeria solar thermal have been developed for various applications, some of these are solar cookers, solar pulverizers, and chick brooding devices [3]. These devices are yet to become household commodities in Nigeria, their uses are only seen in universities and research centres [4].

Several works, $[5 ; 6 ; 7 ; 8$; and 9] have been done in the area of design, performance evaluation, and optimization of the collector units of thermosyphon solar water heaters. Evaluation of the collector losses had been carried out by most of these authors using the Klein model $[6 ; 9]$ of the loss coefficient. Pillar and Agarwal [10] had reported on the optical and thermal losses of the flat-plate collector as a function of the number of the glazing cover, plate emittance, wind velocity and the ambient temperature using Klein model. This research however, utilizes the Malhotra model for the collector overall heat-loss coefficient to investigate the effect of wind speed, number of glazing cover, ambient temperature, gap spacing between collector plate and the glazing cover, collector tilt angle and the plate emissivity on energy losses in the collector. It was observed that, Malhota model is simpler than the Klein's.

Rhushi et al [11] studied and simulated with a computer programme in C-language the performance of a solar water heater using a flat plate collector. The Program calculates instantaneous beam and diffuse radiations for the given location of the collector, number of days for the given date, angle of incidence of beam radiation on the collector, total solar flux incident on the collector, transmissivity - absorbtivity product for beam and diffuse radiations, incident flux absorbed by the absorber plate, collector heat removal factor, overall loss coefficient, water outlet temperature and the instantaneous efficiency. Comparison between simulated results and the collector test results, showed that generalized program predicted the values very near to the experimental values and hence the approach of design analysis based upon mathematical modeling is cheap and efficient compared to the analysis of physical models, which in some cases may become very tedious.

The study is to establish the relationship between collector area and number of glazing, length of collector tube and tank diameter, mass flow rate and volume of the water, air gap spacing between the absorber plate and glazing and the tube spacing and plate thickness on the system solar fraction ( $f$ ) to determine the performance of the system.

\section{METHOD}

The following methods were used for the determination of the system design parameters and characteristics

\subsection{Determination of design parameters}

System design parameters and characteristics were calculated from the programme codes developed in MATLAB programming language using Equations 1 to 25 . The monthly average daily solar radiation and weather data of Bauchi, obtained from the weather data of TRNSYS 16 were used as input for the calculations.

\subsection{Design parameters optimization}

The system design parameters optimization procedure was performed to study the effect and sensitivity of the solar flat plate collector design parameters on the solar fraction (f) of the system in order to determine the proper system characteristics that will give satisfactory performance. Solar radiation, meteorological data and monthly average daily system characteristics for the design month were used as input data into the programme codes written in MATLAB programming language. These programme codes were used to study the effects of varying some selected system characteristics ( e.g collector area, tube spacing, length of the collector tube, mass flow rate, air gap between the absorber plate and the first glazing, tube internal diameter e.t.c) on the chosen design objective function (i.e, solar fraction of the system).

\subsection{Analytical Procedure}

The analytical procedure was carried out using the design equations as follows: 


\subsubsection{Collector heat removal factor}

The collector heat removal factor $F_{R}$, is the ratio of actual useful energy gain of the collector to the useful gain if the whole collector surface were at the fluid inlet temperature, $F_{R}$ is analogous to the heat exchanger effectiveness. For a solar flat plate collector, the collector heat removal factor can be expressed as [12].

$$
F_{R}=\frac{\dot{\mathrm{m}} C_{p}}{A_{c} U_{L}}\left[1-\exp \left(-\frac{A_{c} U_{L F^{\prime}}}{\dot{\mathrm{m}} C_{p}}\right)\right]
$$

Where; $F^{\prime}$ is the collector efficiency factor expressed as;

$$
F^{\prime}=\frac{1 / U_{L}}{W\left[\frac{1}{U_{L}\left[D_{i}+\left(W-D_{i}\right) F\right]}+\frac{1}{C_{b}}+\frac{1}{\pi D_{i} h_{f i}}\right]}
$$

$\mathrm{h}_{\mathrm{fi}}$ is the internal collector fluid heat transfer coefficient and $\mathrm{F}$ is the standard fin efficiency for straight fins with rectangular profile, given as:

$$
F=\frac{\tanh \left[\frac{m\left(W-D_{i}\right)}{2}\right]}{\frac{m\left(W-D_{i}\right)}{2}}
$$

Where;

$$
m=\sqrt{\frac{U_{L}}{K \delta}}
$$

$U_{L}$ is the overall heat transfer coefficient, $K \delta$ is the plate thermal conductivity and thickness product, $D_{i}$ is the internal diameter of tube.

\subsubsection{Collector Top Loss}

An approximate relation for collector top loss coefficient $U_{\text {top }}$ given by [12].

$$
\begin{aligned}
U_{\text {top }}=\frac{\frac{1}{N_{G}}}{\frac{C}{T_{p m}\left[\frac{T p m-T}{N_{G}+f}\right]^{e}}+\frac{1}{h_{w}}} & \\
& +\frac{\left[\sigma\left(T_{p m}^{2}+T_{a}^{2}\right)\left[T_{a}+T_{p m}\right]\right]}{\frac{1}{\varepsilon_{p}+0.00591 N_{G} h_{w}}+\frac{2 N_{G}+f-1+0.133 \varepsilon_{p}}{\varepsilon_{g}}-N_{G}}
\end{aligned}
$$

Where;

$$
\begin{gathered}
f=\left(1+0.089 h_{w}-0.1166 h_{w} \varepsilon_{p}\right)\left(1+0.07866 N_{G}\right) \\
C=520\left[1-0.000051 \beta^{2}\right] \\
\varepsilon_{p}=0.430\left(1-\frac{100}{T_{p m}}\right) \\
T_{p m}=T_{f m}+\left(I \alpha_{p} \tau_{g} / U_{L}\right)\left(1-F_{R}\right)
\end{gathered}
$$

$$
\begin{gathered}
T_{f m}=\frac{\int_{0}^{1} T_{f}(y) d y}{\ell}=T_{f i}+\frac{Q_{U}}{A_{c} U_{L} F_{R}}\left(1-\frac{F_{R}}{F^{1}}\right) \\
h_{w}=5.7+3.8 \times V_{w} \\
\sigma=56.7 \times 10^{-10} \frac{\mathrm{kW}}{\mathrm{m}^{2}} \cdot K^{4}
\end{gathered}
$$

$\sigma$ is the Boltzman's constant

\subsubsection{Collector Useful Energy}

In steady state, the performance of a flat plate solar collector can be described by the useful gain from the collector, $Q_{u}$ which is defined as the difference between the absorbed solar radiation and the thermal loss. Duffie and Beckmann [12] expresses the useful energy gain of a solar collector for glazed or evacuated collector as.

$$
Q_{u}=F_{R} \quad\left[S-U_{L}\left(T_{i}-T_{a}\right)\right]^{+}
$$

The + superscript indicates that only positive values of the terms in the square brackets are to be used. Thus, to produce useful gain greater than zero the absorbed radiation must be greater than the thermal losses.

\subsubsection{Sensible Heat Requirement}

The sensible heat requirement is the energy needed to raise the temperature of water to desired temperature. If water flowing at the rate of $\dot{m} \mathrm{~L}$ is to be heated from a main supplied temperature $T_{i}$ to a desire temperature $T L$, the energy requirement over a specified time horizon may be expressed as follows [13]

$$
Q_{L}=\dot{\mathrm{m}}_{L} C_{p}\left(T_{L}-T_{i}\right)
$$

\subsubsection{Storage Tank Losses}

Losses from the storage tanks may be significant. The rate of tank losses is estimated from the tank loss coefficient- area product (UA)st and the ambient temperature $T_{a}$ surrounding the tank, calculated as [14].

$$
Q_{s t}=U_{s t} A_{s t}\left(T_{s t}-T_{a}\right)
$$

For a cylindrical tank, the surface area of the tank is related to the storage volume of the tank by the following equation [15].

$$
A_{s t}=1.845\left(2+\frac{h}{d}\right) V_{s t}^{\frac{2}{3}}
$$

\subsubsection{Collector and Storage Tank Temperature On the basis of the analysis in [12] and [16], the collector hourly outlet hot fluid temperature $T_{c o}$ is determined by the absorber thermal equilibrium equation as;}




$$
T_{c o}=T_{c i}+\left[T_{a}-T_{c i}+\frac{{ }^{I} T(\tau \alpha)}{U_{L}}\right]\left[1-\exp \left(-\frac{U_{L} A_{c}}{\dot{\mathrm{m}} C_{p}}\right)\right]
$$

Temperature at the inlet of the storage tank could be predicted from the expression [17].

$$
T_{s t i}=T_{c o}+\left(T_{f c o}-T_{a}\right)\left[1-\exp \left(-\frac{U_{o} \pi d_{o} L_{o}}{\dot{\mathrm{m}} C_{p}}\right)\right]
$$

By neglecting the thermal wall resistance, the heat exchange coefficient between the connecting pipes and the ambient conditions can be determined by the equation [18].

$$
U_{o}=\frac{1}{\frac{1}{2 \pi k_{i n s}} \operatorname{Ln}\left(1+\frac{2 t_{i n s}}{d_{o}}\right)+\frac{1}{\pi\left(d_{o}+2 t_{i n s}\right) h_{w}}}
$$

\subsubsection{Storage Tank Temperature}

Assuming solar radiation intensity on tilted surface, ambient temperature, and load demand to be constant over the specified time step, solution of the energy balance equation of the solar water heating system can be obtained using simple Euler's integration, to solve for tank storage temperature $\mathrm{T}^{+}{ }_{\mathrm{st}}[12]$ as;

$$
\begin{array}{r}
T_{s t}^{+}=T_{s t}+\frac{\Delta_{t}}{\left(\rho V_{s t} C_{p}\right)_{s}}\left[Q_{u}-Q_{L s}\right. \\
\left.-U_{s t} A_{s t}\left(T_{s t}-T_{a}\right)\right]
\end{array}
$$

Where; $\Delta \mathrm{t}$ is the time horizon which may be a day, a month or a year depending on the period of interest. For satisfying the entire thermal demand, (solar fraction $S . F=1$ ) storage tank temperature during the time of the demand must be greater than the desired load temperature.

\subsubsection{System Solar Fraction}

The performance of service hot water systems with storage is estimated with $\mathrm{f}$-Chart method. The purpose of the method is to calculate" $f$ " the fraction of the hot water load that is provided by solar heating system (solar fraction). The method enables the calculation of the monthly amount of energy delivered by hot water systems with storage. The fraction $f$ of the monthly total load supplied by the solar water heating system is given as a function of $X$ and $Y$ as;

$$
\begin{gathered}
f=1.029 Y-0.065 X-0.245 Y^{2}+0.0018 X^{2} \\
+0.0215 Y^{3}
\end{gathered}
$$

The two dimensionless groups $\mathrm{X}$ and $\mathrm{Y}$ are defined as:

$$
X=F_{R} U_{L} \times \frac{F_{R}^{I}}{F_{R}} \times\left(T_{\text {ref }}-\overline{T_{a}}\right) \times \Delta t \times \frac{A_{c}}{L}
$$

$$
Y=F_{R}(\tau \alpha)_{n} \times \frac{F_{R}^{I}}{F_{R}} \times \frac{(\overline{\tau \alpha})}{(\tau \alpha)_{n}} \times \overline{H_{T}} N \times \frac{A_{c}}{L}
$$

Where:

$\mathrm{A}_{\mathrm{c}}=$ collector area $\mathrm{m}^{2}$

$\mathrm{F}_{\mathrm{R}}{ }^{1}=$ collector heat exchanger efficiency factor

$\mathrm{U}_{\mathrm{L}}=$ collector overall loss coefficient $\left(\mathrm{W} / \mathrm{m}^{2} .{ }^{0} \mathrm{C}\right)$

$\Delta \mathrm{t}=$ total number of seconds in month

$\mathrm{L}=$ monthly total heating load for space heating and hot water (J)

$\mathrm{T}_{\text {ref }}=$ empirically derived reference temperature $\left(100^{\circ} \mathrm{C}\right)$

$\mathrm{N}=$ days in month

$\overline{T_{a}}=$ monthly average ambient temperature $\left({ }^{\circ} \mathrm{C}\right)$

$\overline{H_{T}}=$ monthly average daily radiation incident on collector surface per unit area $\left(\mathrm{J} / \mathrm{m}^{2}\right)$

$\overline{\tau \alpha}=$ monthly average transmittance-absorptance product [12]. In [12 and [21], the solar fraction as the fraction of the total hot water energy that is supplied by the solar system, is calculated using:

$$
S F=\frac{Q_{L}-Q_{A u x}}{Q_{L}}
$$

Here; $Q_{\llcorner}$is the total energy removed from the system to support the water heating requirement. $\mathrm{Q}_{\text {Aux }}$ is the auxiliary energy supplied to the system to support the portion of the total load that is not provided by the solar energy.

The solar fraction is a better indicator of the system performance compared to the other parameters such as collector efficiency or heat removal factor, since it manifests the overall performance of the entire system not a component.

\subsubsection{Collector Efficiency}

The Hottel - Whillier equation defines the efficiency for a solar collector in terms of the collector heat removal factor $F_{R}$, given in equation form as [14].

$$
\eta_{c}=\frac{Q_{u}}{I_{T} A_{c}}=\frac{F_{R}\left[S-U_{L}\left(T_{i}-T_{a}\right)\right]}{I_{T}}
$$

\section{RESULTS AND DISCUSSION}

\subsection{Collector Area ( $\left.A_{C}\right)$ and number of glazing (N)}

Figure 1 shows the effect of collector area and the number of glazing on the system solar fraction. These parameters significantly contribute to the solar fraction of the system. Increasing the collector surface area increases the solar fraction of the system. As the 
collector area increases from $0.1 \mathrm{~m}^{2}$ to $5 \mathrm{~m}^{2}$ with increase in the number of glazing, the solar fraction increases. With collector area of $5 \mathrm{~m}^{2}$, single glazing, $82 \%$ solar fraction was achieved and with double glazing, $97 \%$ system solar fraction was achieved. It clearly shows that as the number of glazing increases it requires a small collector area to achieve higher percentage of system solar fraction, hence resulting in improved overall system performance. This finding agrees with an earlier work of $[9 ; 23]$. The glazing cover reduces the radiation heat losses from the hot absorber plate since glass being transparent to the solar radiation is a good absorber of thermal energy since it is nearly opaque to the long wave thermal radiation from the absorber to the surroundings.

\subsection{Length of collector tube (L) and tube diameter (DT)}

Figure 2 shows the effect of the length of the collector and the diameter of the tank on the system solar fraction. From the Figure, it can be seen that as the length of the tube increases, solar fraction also increases, but the solar fraction decreases with increase in the diameter/volume of the tank. With the tank diameter of $0.1 \mathrm{~m}$ to $0.4 \mathrm{~m}$ an average of $75 \%$ system solar fraction was achieved. This implies that, as the number of turns of the flow tube increases, the system solar fraction increases, but decreases with the volume of the tank. This finding is line with the works of $[24 ; 25]$.

\subsection{Effect of mass flow rate $(\dot{m})$ and volume of water (Vol.) on the system solar fraction}

Figure 3 revealed that as the mass flow rate increases, the system solar fraction increases, but decreases as the volume of water increases. It can be observed that, from the mass flow rate of $1 \mathrm{~kg} / \mathrm{s}$ to $0.008 \mathrm{~kg} / \mathrm{s}$, the flow rate is laminar (i.e $\operatorname{Re}<2100$ ) with a volume of $0.088 \mathrm{~m}^{3}$. Above $0.008 \mathrm{~kg} / \mathrm{s}$, there is a sudden rise in the flow indicating that, the flow is about changing from laminar to turbulent flow (i.e Re> 2100). Also with the increase in the volume of water $\left(0.130 \mathrm{~m}^{3}\right.$ to $\left.0.200 \mathrm{~m}^{3}\right)$, the flow is still laminar. This implies that, increasing the mass flow rate has a minimal effect on solar fraction; however, reducing the volume of water has a shape effect on the solar fraction. Increasing the volume of the water means increasing the mass flow rate for normal operation. This finding agrees with the earlier works of $[21 ; 26]$.

\subsection{Air gap spacing between the absorber plate and the glazing}

Figure 4 shows the effect of air gap spacing between the absorber plate and the glazing. This parameter is one of the factors that contribute to the overall collector loss coefficient. Optimizing the gap reduces convective heat losses from the absorber plate to the glazing. This implies that, as the air gap increases, the top heat loss increases and decreases as the number of glazing increases. This finding is in line with the earlier work of $[9 ; 27]$, they reported that, a gap width that is greater than $5 \mathrm{~cm}(0.05 \mathrm{~m})$ is suitable for optimum system performance.

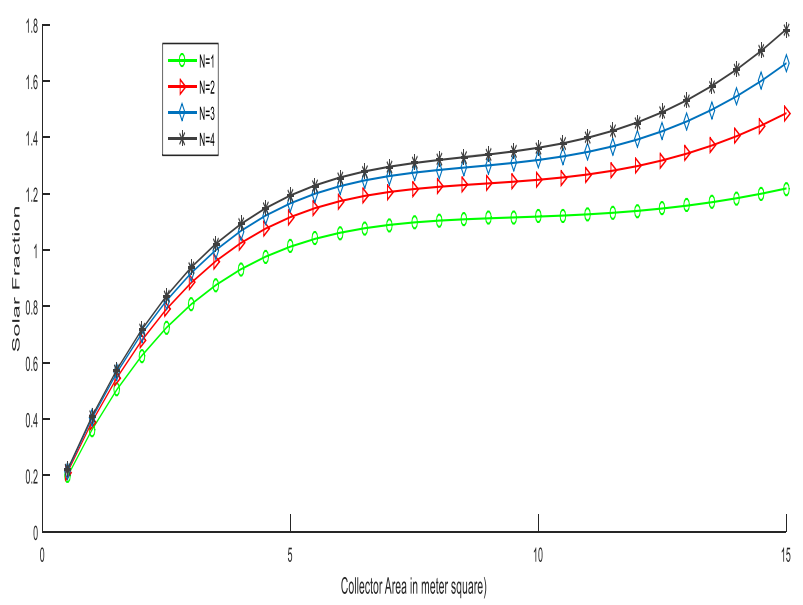

Figure 1: Effect of collector area and number of glazing on system solar fraction

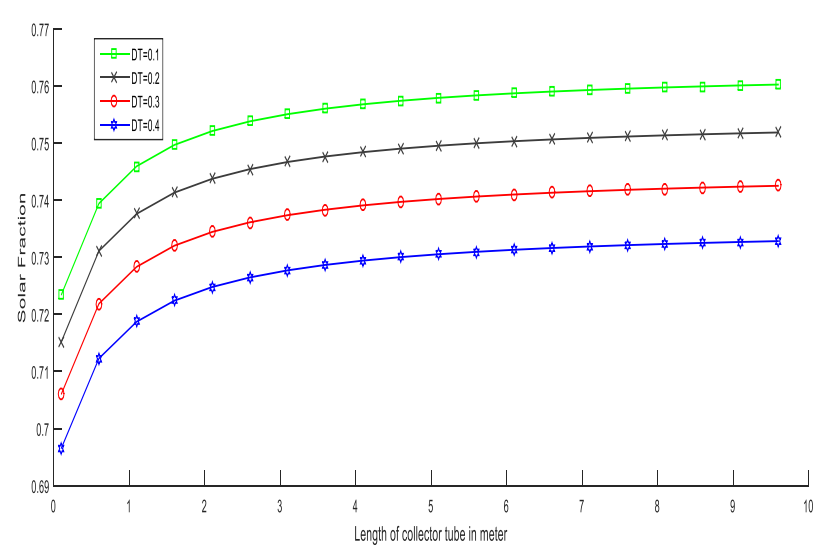

Figure 2: Effect of length of collector tube and tube diameter on the system solar fraction 


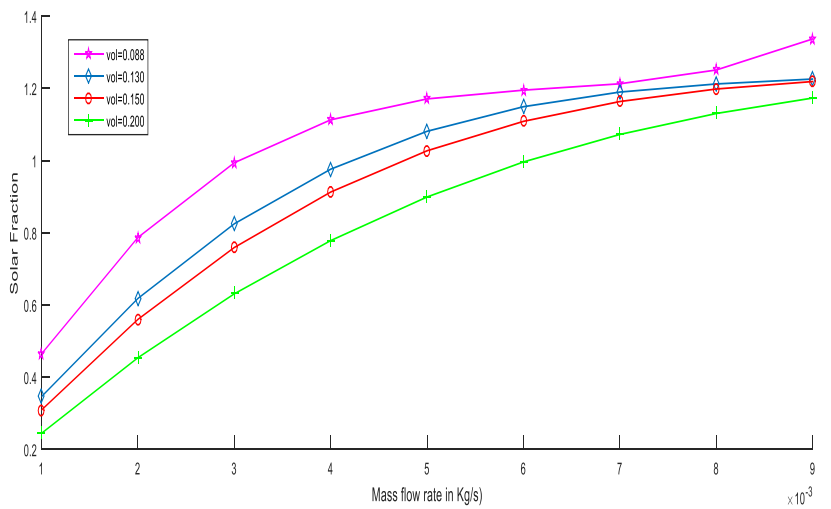

Figure 3: Effect of mass flow rate and volume of water on the system solar fraction

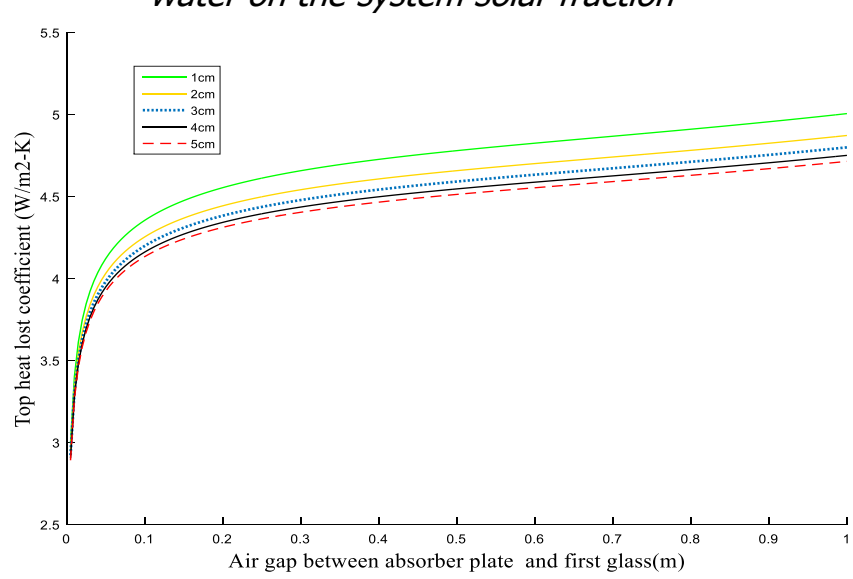

Figure 4: Effect of air gap spacing between the absorber plates and glazing

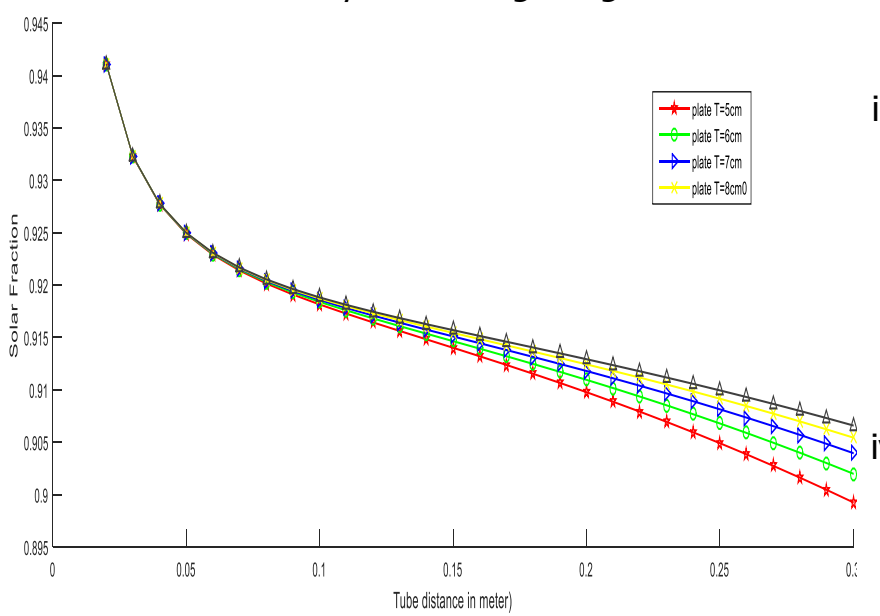

Figure 5: Effect of tube spacing and plate thickness on the system solar fraction

\subsection{Tube spacing and plate thickness $(T)$}

Figure 5 shows the effect of tube spacing, and plate thickness on the system solar fraction. The Figure shows that, as the tube spacing increases, the solar fraction decreases and as the plate thickness increases, the solar fraction increases slightly. The plate thickness increase is considered very insignificant, considering the system cost in relation to system performance.

\section{CONCLUSION}

Parametric studies which study the effect and sensitivity of some selected system components on the system solar fraction were studied through programmed written in MATLAB programming language in order to determine the appropriate components size for each component of the system based on solar radiation and weather data of Bauchi. The parametric study revealed that the system solar fraction is affected in the following ways:

i. Increasing the collector surface area increases the system solar fraction. As the collector area increases from $0.1 \mathrm{~m}^{2}$ to $15 \mathrm{~m}^{2}$ with increase in the number of glazing, the solar fraction increases. With collector area of $0.1 \mathrm{~m}^{2}$ to $5 \mathrm{~m}^{2}$, single glazing, $82 \%$ solar fraction was achieved and with double glazing $97 \%$ system solar fraction was achieved.

ii. Increasing the length of the tube increases the system solar fraction, but, the solar fraction decreases with increase in the diameter of the tank. With tank diameter of $0.1 \mathrm{~m}$ to $0.4 \mathrm{~m}$ an average of $75 \%$ system solar fraction was achieved. This implies that, as the number of turns of the flow tube increases, the system solar fraction increases, but, decreases with the diameter of the tank.

iii. Optimizing the air gap between the absorber plate and the glazing reduces convective heat losses. This implies that, as the air gap increases, the top heat loss increases and decreases as the number of glazing increases. A gap width of $0.045 \mathrm{~m}$ $(4.5 \mathrm{~cm})$ to $0.05 \mathrm{~m}(5 \mathrm{~cm})$ was suitable for optimum system performance.

iv. Increasing the tube spacing, the system solar fraction decreases and as the plate thickness increases, the solar fraction increases slightly. The plate thickness increase is considered very insignificant, considering the system cost in relation to system performance.

\section{REFERENCES}

[1] Gerg, H. P. and Prakash, J. Solar Energy Fundamentals and Applications, Tata McGraw-hill Publishing Company Ltd New Delhi, 2014.

[2] Energy Commission of Nigeria (ECN), National Workshop on Review of Renewable Energy Master Plan Abuja, Nigeria, 2016. 
[3] Musa, U, Sambo, A. S and Bala, E. J. "Design, Construction and Performance of a Parabolic Concentrator Cooker", Nigerian Journal of Solar Energy, Vol.10, Number 2, 2000, pp. $19-25$.

[4] Enibe, S. O. "Recent Advances in Renewable Energy Applications in Nigeria and their Policy Implications", Proc. First Workshop of the
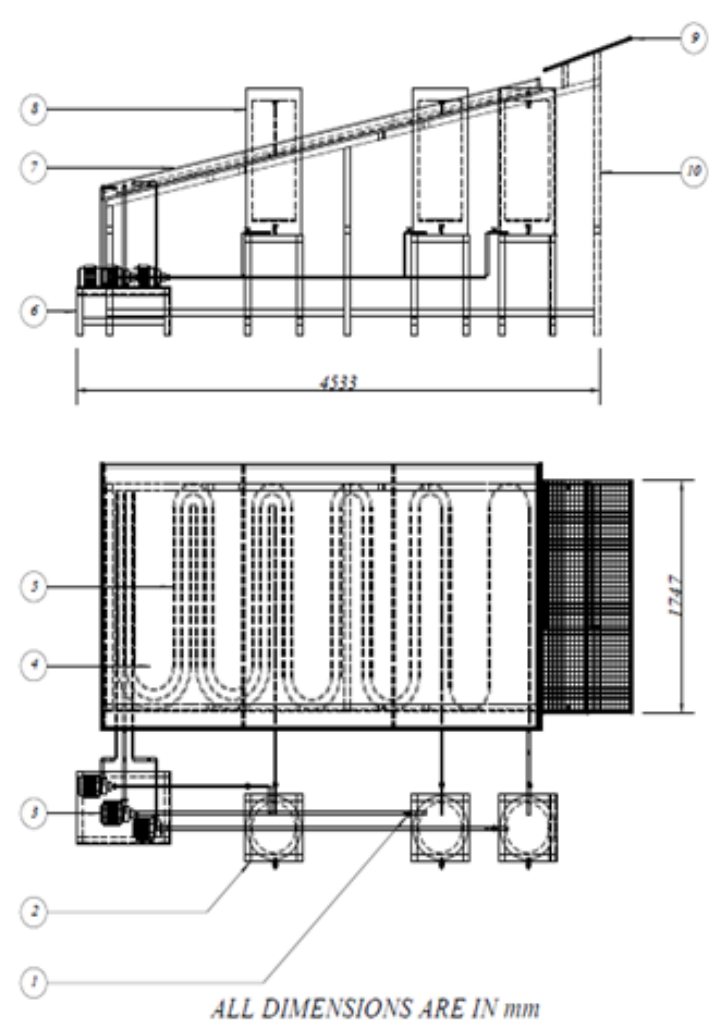

Renewable Energy Sub-National of the African Network of Scientific and Technological Institutions (ANSTI) Kumasi, Ghana, April, 13-16, 2017, pp. 134-141.

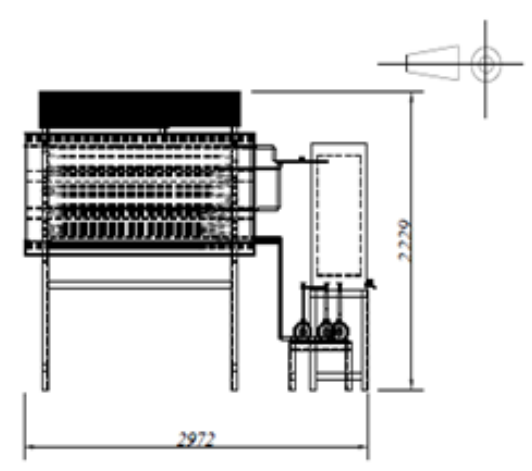

Figure 6: Schematic Illustration of the System

[5] Yeh, H. M, Ho, C. D and Yeh, C. W. "Effect of Aspect Ratio on the Collector Efficiency of Sheet and Tube Solar Water Heater with the Consideration of Hydraulic Dissipated Energy", Renewable Energy, Vol. 28,Number 6, 2015, pp. 1575-1586.

[6] Mumah, S. N. "Sizing and Performance Evaluation of a Flat Plate Collector for a Solar Absorption Refrigeration System", Nig. J. Solar Energy, Vol.13, Number 2, 2017, pp., $67-75$.

[7] Morrison, G. L and Braun, J. S. "System Modeling and Operating Characteristics of a Solar Flate Plate Water Heater", Solar Energy, Vol. 34, Number 24, 2017, pp. $389-405$

[8] Eisenman, W. K, Vajen and Ackermann, H. "On the Correlations Between Collector Efficiency Factor and Material Content of Parallel Flow Flat Plate
Solar Collectors", Solar Energy, Vol. 76, Number 3, 2014, pp. 381-387.

[9] Agbo, S. N and Unachukwu, G. O. "Performance Evaluation and Optimization of the NCERD Thermosyphon Solar Water Heater", Proc. World Renewable Energy Congress, Aug, 19-25, 2006, Florence, Italy.

[10] Pillar, P. K and Agarwal, R. C. "Factors Influencing Solar Energy Collector Efficiency", Applied Energy, Vol. 8, Number 5, 2009, pp. $205-213$.

[11] Rhushi P and Byregowda. "Experiment Analysis of a Flat Plate Collector and Comparison of Performance with Tracking Collector", Department of Mechanical Engineering GSS Institute of Technology, Bangolore Euro Journal Publishing Vol 23, Number 3, 2017, pp. $132-147$ 
[12] Duffie, J. A and Beckman, W. A. Solar Engineering of Thermal Process $5^{\text {rd }}$ Edition, John Willey and Sons New York, 2006

[13] Alireza, H. and Kamran, S. "Optimal Design of a Forced Circulation Solar Water Heating System for a Residential Unit in Cold Climate using TRNSYS", Solar Energy, Vol. 83, Number5, 2009, pp. 700714.

[14] Govind N. K, Shireesh B. K and Sartanu B. "Design of Solar Systems Utilizing Pressurized Hot Water", Solar Energy, Vol. 82, Number 23, 2011, pp. 686 $-699$.

[15] Kulkarni, G. N, Kedare, S. B, and Bandyopadhyay, S. "The Concept of Design Space for Sizing Solar Hot Water Systems", Solar Energy, Vol. 12, Number 3, 2017, pp. $283-298$.

[16] Javelas, R. and Pierson P. "Theoretical and Experimental Study of a Natural Circulation type Solar Water Heater with Exchanger", $R e^{\prime \prime} v$, Gen Thermique; Vol. 259, Number 21, 2007, pp. $67-$ 82.

[17] Koffi, P. M. E, Andoh, H. Y, Gbaha P, Toure S, and Ado G. "Theoretical and Experimental Study of a Solar Water Heater with Internal Exchanger using Thermosyphon System", Energy Conversion and Management, Vol. 49, Number 23, 2008, pp. 2279 $-2290$.
[18] Qin L. "Analysis, Modeling and Optimum Design of Solar Domestic Hot Water System. (Doctoral Dissertation, University of Wisconsin)", retrieved March 28, 2016 from http//sel.me, wisc.edu/thesis.

[19] Buckles, W. E, and Klein, S. A. "Analysis of Solar Domestic Hot Water Heaters", Solar Energy, Vol. 25, Number 5, 1980. Pp. 417- 424.

[20] Parker, G. J. "Evaluation of a House Solar Water Heating System Procedure", Solar Energy, Vol. 26, Number 3, 2014, pp. 213-222.

[21] Shariah, A. M and Shialabi, B. "Optimal Design for a Thermosyphon Solar Flat Plate Water Heater", Renewable Energy, Vol. 11, Number 12, 2017, pp. $351-361$.

[22]Badescu, V. "Optimal Control of Flow in Solar Collector System with fully mixed Water Storage Tank", Energy Conversion and Management, Vol. 49, Number 2, 2008, pp. 169-184.

[23] Bequette B. W. Process Control Modeling, Design and Simulation, It $^{\text {st }}$ ed. Prentice Hall, New York, 2017.

[24] Delfin, S. S, Carlos, R. E and Valentine, C. H. "Simulation of a Solar Domestic Water Heating System with different Collector Efficiency and different Volume Storage Tanks", Retrieved April 6, $2017 \mathrm{from} \mathrm{htt//sel.me.wisc.edu.}$ 